\title{
Fermentation of Microalgae Biomass through Mild Acid Pretreatment for Bioethanol Production
}

\author{
Lee Muei Chng ${ }^{1,2^{*}}$, Kenneth S.K. Teo ${ }^{1}$, Derek Juinn Chieh Chan², Keat Teong Lee ${ }^{2}$, Pey Yi Toh ${ }^{1,2}$ \\ ${ }^{1}$ Department of Petrochemical Engineering, Faculty of Engineering and Green Technology, Universiti Tunku \\ Abdul Rahman, 31900 Kampar, Perak, Malaysia \\ ${ }^{2}$ School of Chemical Engineering, Universiti Sains Malaysia, Seri Ampangan, 14300 Nibong Tebal, Pulau Pinang, \\ Malaysia \\ *Corresponding author: chnglm@utar.edu.my
}

\section{Article History}

Received: May 7, 2018

Received in revised form: November 1, 2018

Accepted: November 17, 2018

Published Online: February 10, 2019

\begin{abstract}
Conversion of microalgae biomass to bioethanol is actively being researched to establish a cost effective and sustainable production technology. The main challenge is to break down the carbohydrates content in the biomass to obtain fermentable sugar for subsequent fermentation process. This study focuses on the effectiveness of the usage phosphoric acid pretreatment and capability of Saccharomyces diastaticus as the fermentation microbe to produce ethanol. Scenedesmus dimorphus microalgae biomass was used as the feedstock due to its high carbohydrate content. Mild acid hydrolysis at various conditions were carried out on biomass and the hydrolysates were subjected to fermentation. The optimum condition of acid pre-treatment using phosphoric acid was determined in this study. Based on the results, bioethanol yield of $94 \%$ was obtained at optimum condition of $2.5 \% \mathrm{v} / \mathrm{v}$ phosphoric acid at temperature of $120{ }^{\circ} \mathrm{C}$ for $30 \mathrm{~min}$. This study proved that combination of phosphoric acid pre-treatment process with Saccharomyces diastaticus yeast provides a practicable method for the production of bioethanol from microalgae.
\end{abstract}

Keywords: Mild acid treatment; Scenedesmus dimorphus; Saccharomyces diastaticus; bioethanol

\subsection{INTRODUCTION}

The use of bioethanol as an alternative energy source is becoming more extensive lately especially in the field of transportation. Thus, demand for feedstock to produce bioethanol increases drastically. However, most of the bioethanol production uses food crops such as sugarcane or corn as the feedstock to produce bioethanol have to go through a series of complex process [1]. Recently, microalgae were introduced as promising feedstock for bioethanol production due to its simple cell structure and are able to utilize carbon dioxide and nutrients via photosynthesis to convert them into valuable compounds especially carbohydrate [2]. Besides that, cultivation of microalgae is relatively easy to be done due to its rapid growth rate and stable growth in all seasons. Moreover, the absence of lignocellulosic materials in their cells avoids the need of complex saccharification and hydrolysis process for subsequent fermentation [3].

Researchers have shown that microalgae species such as Chlorella, Dunaliella, Chlamydomonas and Scenedesmus contain higher amount carbohydrate of about 30-50 \% w/w at dry basis, which are suitable for biofuel production [4]. Scenedesmus dimorphus is used as biomass in this study due to its high carbohydrates content and simple in structure, as well as potentially to be growth for mass scale production [5]. Based on the study done by Biller and Ross [6], Scenedesmus species have higher carbohydrates contents compared to other species at a range of 19-46\% w/w and most of them store their carbohydrate as starch.

Pretreatment of microalgae is an important process to convert the insoluble carbohydrate into soluble fermentable sugar. Direct fermentation of microalgae with yeast is not applicable as the carbohydrate in the microalgae cell is not accessible and digestible 
by yeast. This is due to the presence of cell wall which prevents the carbohydrate to be readily soluble in the medium [7]. In addition, most of the fermenting microbe only consumes simple sugar such as glucose and galactose. Thus, disruption of the cell wall via pre-treatment is needed in order to release the starch. The released polysaccharides required further disintegration process to become simple sugar which is fermentable for bioethanol production.

In order to produce monomeric sugar constituents which are fermentable by yeast, two main types of hydrolysis methods mainly acid hydrolysis and enzymatic hydrolysis are used. Acid hydrolysis is a low cost process compared to enzymatic hydrolysis. The general concept of acid hydrolysis involves breaking of cell wall and degradation of starch into fermentable sugar. The yield of fermentable sugar and the rate of reaction is higher compared to other type of hydrolysis [8]. Sulphuric acid, phosphoric acid and hydrochloric acid are the three common acids for hydrolysis. The use of sulphuric acid at high temperature provides a higher yield of simple sugar with a short reaction time [9]. However, the risk of inhibitors forming is also high. On the other hand, mild phosphoric acid is able to hydrolyse the cell wall and the presence of phosphorus compound in the mixture is able to serve as a nutrient for yeast to grow, which increases the fermentation rate [10]. However, acid hydrolysis conditions have to be properly monitored to avoid formation of side products which is toxic towards the yeast [11].

Saccharomyces cerevisiae is the conventional yeast used for fermentation as $S$. cerevisiae provides a high yield of bioethanol as well as high fermentation rate [12]. Besides that, S. cerevisiae have high tolerance against inhibitors and have higher resistance towards bioethanol toxicity. However, S. cerevisiae is not able to consume starch directly to produce bioethanol [13] which in turn lead to a series of pretreatment process to break the starch to simple sugar for ethanol production process. The overall process could be optimized by utilizing amylolytic yeast, Saccharomyces diastaticus. The employment of $S$. diastaticus is able to condense the hydrolysis process and fermentation process into a single step operation by fermenting the starch to bioethanol directly [14]. Based on the research done by Pothiraj et.al [15], the starch saccharification potential of S. diastaticus is higher as the yield and total reaction time used by $S$. diastaticus for direct fermentation of cassava waste was superior as compared to fungal. However, studies on fermentation behaviour of $S$. diastaticus in bioethanol production are scarcely reported.

Therefore, the focus in this study was the use of phosphoric acid instead of sulphuric acid in the pretreatment of microalga biomass. The operating conditions for the pre-treatment process were manipulated to analyze the effect of the respective factor to subsequent fermentation process. Therefore, a proper integrated approach can be established here to optimize the bioethanol yield from microalgae by utilising $S$. diastaticus to ferment mild acid hydrolysate. This can avoids the formation of inhibitors which are caused by high acid concentration at extreme condition; meanwhile improve the current bioethanol production technology.

\subsection{METHODOLOGY}

\subsection{Materials}

A pure culture of yeast, Saccharomyces diastaticus (ATCC 28338) was purchased from American Type Culture Collection (ATCC). Dried microalgae biomass of Scenedesmus dimorphus (UTEX 1237, University of Texas) was obtained from School of Chemical Engineering, Universiti Sains Malaysia (USM, Malaysia).

\subsection{Characterisation of Microalgae Biomass}

A modified method based on National Renewable Energy Laboratory was used to quantify the carbohydrate content in the biomass [16]. A two steps hydrolysis was used as the hydrolysis method for the biomass where the hydrolysis agent used is sulphuric acid. Dry microalgae biomass with amount of $300 \mathrm{mg}$ was added into test tube. After that, $3 \mathrm{~mL}$ of $72 \mathrm{wt} \%$ of $\mathrm{H}_{2} \mathrm{SO}_{4}$ was added into the tube. The mixture was placed in a water bath at constant temperature of $30{ }^{\circ} \mathrm{C}$ and stirred for $1 \mathrm{hr}$. After that, the sample was transferred to a $250 \mathrm{~mL}$ of Schott bottle and $84 \mathrm{~mL}$ of deionised water was added into the sample bottle. The sample was further hydrolysed at constant temperature of $121{ }^{\circ} \mathrm{C}$ for 1 hour by using autoclave. After that, the sample was cooled and neutralised to $\mathrm{pH} 3$ by using $2 \mathrm{~N}$ of aqueous sodium hydroxide. The mixture was then centrifuged at $3000 \mathrm{rpm}$ for $30 \mathrm{~min}$ and the supernatant were subjected to HPLC analysis for total carbohydrate analysis.

A modified method based on National Renewable Energy Laboratory was used to quantify the starch content in the biomass. Amyloglucosidase was used as the hydrolysis enzyme [17]. A total weight of $100 \mathrm{mg}$ of dry microalgae was added into a boiling tube followed by $5 \mathrm{~mL}$ of distilled water. After that, $1 \mathrm{~mL}$ of $2 \mathrm{~N} \mathrm{NaOH}$ was added and the mixture was stirred in a preheated water bath at constant temperature of $90{ }^{\circ} \mathrm{C}$. After 20 min of stirring, $1 \mathrm{~mL}$ of $2 \mathrm{~N} \mathrm{HCl}$ was added to neutralise the solution. The solution was then cooled to temperature below $50{ }^{\circ} \mathrm{C}$. After that, $2 \mathrm{~mL}$ of acetate buffer at $\mathrm{pH} 4.5$ was added into the solution followed by addition of $0.5 \mathrm{~mL}$ of amyloglucosidase ( 60 units of activity per milliliter). The solution was stirred at $40{ }^{\circ} \mathrm{C}$ for approximately $60 \mathrm{~min}$. The solids were removed via centrifugation at $3000 \mathrm{rpm}$ for $15 \mathrm{~min}$. The supernatant was analysed for its composition using HPLC. 


\subsection{Acid Pretreatment of Biomass}

Pretreatment of microalgae at various conditions was investigated using phosphoric acid as the hydrolysis agent. The pretreatment of biomass was carried out in a $250 \mathrm{~mL}$ Schott bottle. The amount of biomass is fixed at a constant value of $1 \mathrm{~g}$. The phosphoric acid solution was prepared by diluting concentrated phosphoric acid with distilled water to obtain acid concentration of $0.5 \%$ to $2.5 \% \mathrm{v} / \mathrm{v}$. 1 gram of microalgae biomass was then added into a reaction bottle. $50 \mathrm{~mL}$ of phosphoric acid at the investigated concentration were added into the bottle. The mixture was stirred for 30 min using magnetic stirrer at room temperature to ensure homogeneous mixing. After that, the mixture was hydrolysed with an autoclave at a predetermined temperature $\left(115^{\circ} \mathrm{C}, 120^{\circ} \mathrm{C}\right.$ and $125^{\circ} \mathrm{C}$ ) and duration $(15 \mathrm{~min}, 30 \mathrm{~min}$ and $45 \mathrm{~min})$. Upon the completion of treatment, the mixture was stirred for $30 \mathrm{~min}$ at constant speed at room temperature. After that, the samples were centrifuged at $3000 \mathrm{rpm}$ for $30 \mathrm{~min}$. The liquid solution were collected and subjected to subsequent fermentation and HPLC analysis.

\subsection{Pre-culture of Saccharomyces diastaticus as Fermentation Medium}

Saccharomyces diastaticus was added into $150 \mathrm{~mL}$ of medium consists of $10 \mathrm{~g} / \mathrm{L}$ of dextrose, $3 \mathrm{~g} / \mathrm{L}$ of yeast extract, and $5 \mathrm{~g} / \mathrm{L}$ of peptone. The yeast culture was maintained in water bath shaker for 12 hours at $30^{\circ} \mathrm{C}$.

\subsection{Fermentation}

A total of $30 \mathrm{~mL}$ of the pre-treated solution were added into a conical flask. It is then diluted with $10 \mathrm{~mL}$ of distilled water. Yeast extract at $3 \mathrm{~g} / \mathrm{L}$ and $5 \mathrm{~g} / \mathrm{L}$ of peptone were added into the solution. Then, the $\mathrm{pH}$ of the solution was adjusted to $\mathrm{pH} 6 \mathrm{using}$ $2 \mathrm{~N}$ of $\mathrm{NaOH}$. The mixture was sterilised with an autoclave at $121{ }^{\circ} \mathrm{C}$ for $20 \mathrm{~min}$. After sterilising, the mixture was allowed to cool to room temperature. A volume of $5 \mathrm{~mL}$ of pre-cultured Saccharomyces diastaticus was centrifuged at $3000 \mathrm{rpm}$ for 15 min. The supernatant was removed and $5 \mathrm{~mL}$ of deionised water were added into the yeast cell which is used as inoculums for fermentation. The yeast solution were added into the sterilised solution and placed in an orbital shaker at constant temperature of $30^{\circ} \mathrm{C}$ and $120 \mathrm{rpm}$. The initial total working volume of fermentation was $45 \mathrm{~mL}$. Sample of $1 \mathrm{~mL}$ was taken from fermentation broth after $24 \mathrm{hr}$ and $48 \mathrm{hr}$ of fermentation time. The samples were subjected to HPLC analysis for the sugar content and bioethanol content quantification.

The maximum theoretical yield of bioethanol is at $51.1 \%$. It is limited by the nature of fermentation where equation (1) was used to determine the yield of bioethanol based on the total sugar available while taking the maximum theoretical yield into account.

$$
\text { Bioethanol Yield, } \%=\frac{\text { Ethanol }(\mathrm{g})}{\text { Total Sugar }(\mathrm{g}) \times 0.511} \times 100
$$

where 0.511 is the maximum theoretical conversion of sugar to ethanol.

\subsection{Instrumental Analysis Method}

Sugar content measurement and bioethanol content determination were carried out with high performance liquid chromatography (Shimadzu) system equipped with refractive index detector (Aminex-HPX-87H, 300 x 7.8mm column). The column was placed in an oven at constant temperature of $50{ }^{\circ} \mathrm{C}$. Sulphuric acid at concentration of $0.005 \mathrm{M}$ of was used as the mobile phase and the flow rate was set at $0.6 \mathrm{~mL} / \mathrm{min}$. Calibration curve were constructed using standard glucose and ethanol. Quantification of glucose content and bioethanol content were determined based on the calibration curve.

The HPLC system (Agilent series 1200) is use to analyse acid hydrolysates. The detector for analysis is evaporative light scattering detector running at temperature of $80{ }^{\circ} \mathrm{C}$ with deionized water as the mobile phase. The analysis was run with Hi-Plex Ca column at a flow rate of $0.6 \mathrm{~mL} / \mathrm{min}$. A set of sugar standard (glucose, mannose, galactose and dextrin) with concentration range from $0.2 \mathrm{mg} / \mathrm{mL}$ to $1 \mathrm{mg} / \mathrm{mL}$ were injected to construct the calibration curve.

\subsection{RESULTS AND DISCUSSION}

\subsection{Microalgae Biomass Characterization}

Scenedesmus dimorphus microalgae constitute of carbohydrate that is contributed by cell wall build from cellulose and stored energy in the form of starch. HPLC analysis of solution using Hi-Plex Ca column after the two-step acid hydrolysis indicated 
the presence of glucose, galactose and cellobiose. Most of the content detected was glucose, which is about $36 \%$ w/w, while about $4.5 \% \mathrm{w} / \mathrm{w}$ is cellobiose and $4 \% \mathrm{w} / \mathrm{w}$ is galactose. As the result, the total carbohydrate content of Scenedesmus dimorphus is about $44.5 \%$ on dry weight basis. Therefore, the total equivalent glucose produced from microalgae biomass for a complete hydrolysis is approximately $44 \pm 0.5 \% \mathrm{w} / \mathrm{w}$.

As for the total starch quantification, it is carried out with the use of amyloglucosidase as the enzyme. Amyloglucosidase selectively hydrolysed starch into glucose. The amount of glucose was determined based on the glucose standard calibration curve. The amount of glucose produced is equals to the amount of starch presence in the biomass as amyloglucosidase selectively converts starch to glucose. The total starch content of Scenedesmus dimorphus biomass is about $28 \pm 0.5 \%$ w/w. Based on the results obtained, Scenedesmus dimorphus consist significant amount of carbohydrates that are potential for subsequent fermentation process to produce bioethanol.

\subsection{Performance of Mild Acid Pretreatment}

\subsubsection{Effect of Acid Concentration on the Total Glucose Produced}

The concentration of the acid in pretreatment plays an important role in manipulating the amount of glucose produced, which is the most preferred sugar by yeast. Figure 1 show the effect of acid concentration to glucose yield. It is observed that glucose concentration increased when acid concentration increases from $0.5 \% \mathrm{v} / \mathrm{v}$ to $2.5 \% \mathrm{v} / \mathrm{v}$. The yield of glucose produced is the lowest $(0.6 \mathrm{~g} / \mathrm{L})$ at lowest acid concentration. Whereas highest acid concentration produced highest amount of glucose, at approximately $2 \mathrm{~g} / \mathrm{L}$. Based on the HPLC chromatogram, mixture of monomeric (glucose and galactose) and oligomeric sugars were detected in the hydrolysates. Oligomeric sugars are mostly found in the mixture and the peaks become weaker in HPLC chromatogram when acid concentration increased. The oligomeric sugars were produced due to the partial hydrolysis of mild acid treatment condition. However, the presence of these sugars could still contribute to the amount of bioethanol produced as well [18].

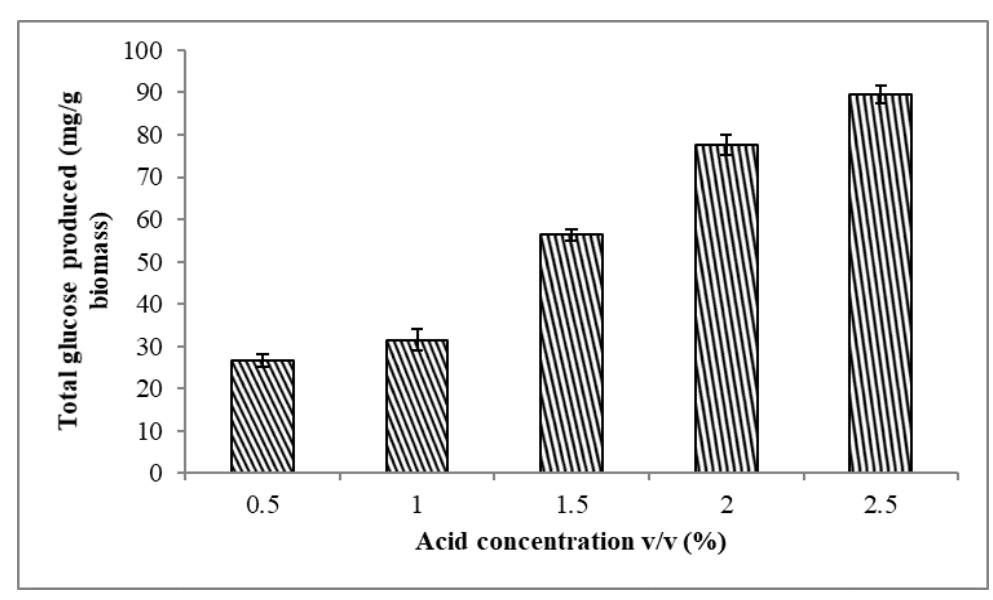

Figure 1. Effect of acid concentration in pretreatment to produce glucose. The pretreatment temperature and duration were maintained at $120{ }^{\circ} \mathrm{C}$ and $30 \mathrm{~min}$ respectively.

It is observed that higher acid concentration enables more cleavages of glycosidic linkage in polysaccharides thus enhanced the amount of sugar produced. The hydrogen exist in aqueous phosphoric acid are react with glycosidic oxygen of polysaccharides and eventually break down the glycosidic linkage under influence of high temperature. The presence of oligomeric and monomeric sugars after the treatment process proved that phosphoric acid is able to catalyse the hydrolysis of carbohydrates in microalgae biomass and converts them to fermentable sugar.

\subsubsection{Effect of Pretreatment Temperature on the Total Glucose Produced}

The reaction temperature is one of the main factors that affect the efficiency of microalgae pretreatment as illustrated in Figure 2. Glucose produced increased with the increase of reaction temperature, where $1.0 \mathrm{~g} / \mathrm{L}$ and $2.5 \mathrm{~g} / \mathrm{L}$ of glucose were produced at temperature of $115{ }^{\circ} \mathrm{C}$ and $125{ }^{\circ} \mathrm{C}$, respectively. Figure 2 shows that total glucose produced increase drastically with investigated pre-treatment temperature. Therefore, degradation of microalgae cell wall is favoured at higher temperature. HPLC analysis performed exhibited similar profile as discussed in acid concentration effect where by hydrolysates at various temperature depicted mixtures of simple sugar and oligosaccharides. At $125{ }^{\circ} \mathrm{C}$, the degradation of the cell wall occurred 
extensively exposing the carbohydrates content within the cell to the acidic environment. Thus, a higher amount of fermentable sugar was achieved.

One of the issues that arise when using high reaction temperature is the formation of inhibitors from the degradation of organic compounds [13]. The degraded carbohydrates such as furfural and 5-hydroxymethylfurfural acts as an inhibitor which inhibits the fermentation process [19]. However, in this study, the reaction temperature up to $125^{\circ} \mathrm{C}$ has yet to produce any of the known inhibitors as analysed by HPLC.

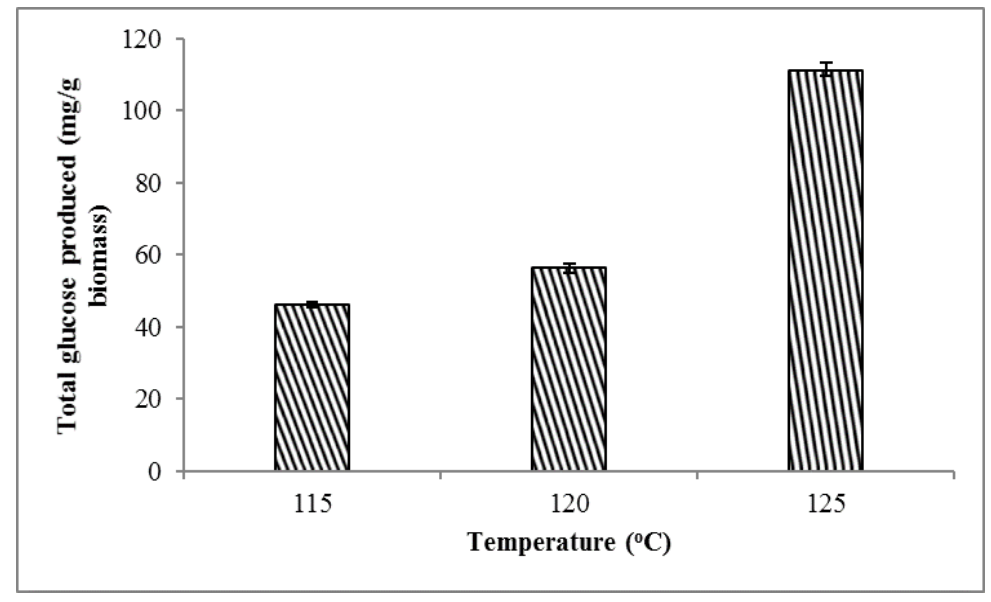

Figure 2. Effect of temperature in pretreatment to produce glucose. The acid concentration and pre-treatment duration were maintained at $1.5 \% \mathrm{v} / \mathrm{v}$ and $30 \mathrm{~min}$ respectively.

\subsubsection{Effect of Pretreatment Time on the Total Glucose Produced}

The duration for the pretreatment of microalgae affects the total glucose produced. Based on Figure 3, the increase in reaction time resulted in the increment of glucose concentration. The shortest pretreatment time which is 15 min produced the lowest amount of glucose at about $1.1 \mathrm{~g} / \mathrm{L}$. Drastic increase in glucose concentration was observed when duration of pretreatment was increased from $30 \mathrm{~min}$ to $45 \mathrm{~min}$. The yield of glucose is the highest with concentration of $2.1 \mathrm{~g} / \mathrm{L}$ at $45 \mathrm{~min}$. Other than glucose, most of the carbohydrate was degraded to oligomers as analysed by HPLC. A longer pretreatment time provides sufficient time for the degradation of the cell wall to occur. In addition, longer residence time allows a higher degree of conversion of released polysaccharides, which is starch to simple sugar.

However, for a longer pretreatment time, there are potential of the decomposition of carbohydrates to undesired product. By referring to the amount of carbohydrates indicated in Figure 3, the decomposition of carbohydrates seems has yet to occur as there is significant increase in total glucose produced at $45 \mathrm{~min}$ of pre-treatment time.

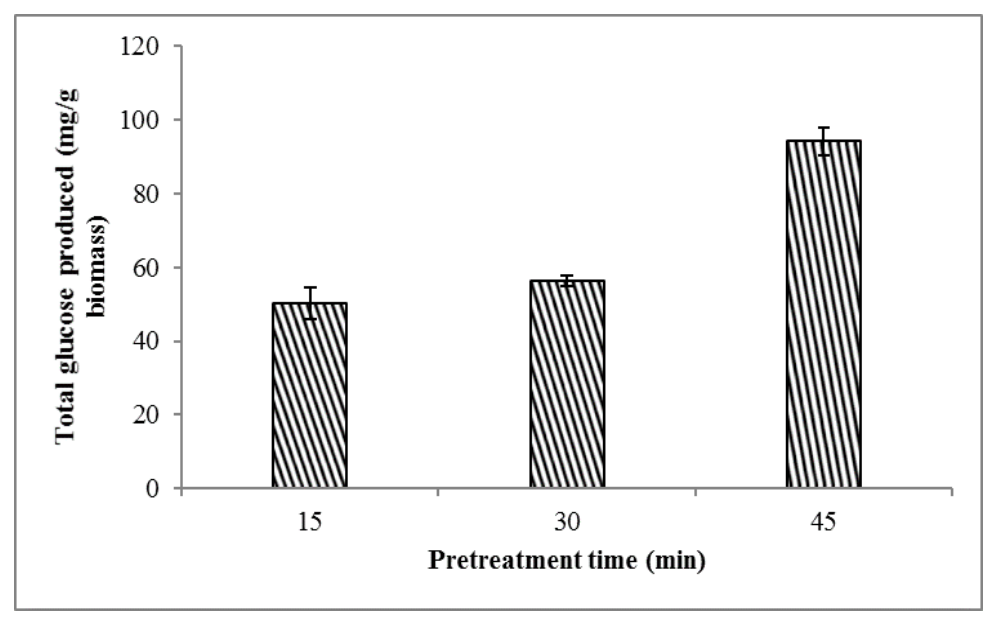

Figure 3. Effect of time in pretreatment to produce glucose. The acid concentration and pretreatment temperature were maintained at $1.5 \% \mathrm{v} / \mathrm{v}$ and $120^{\circ} \mathrm{C}$ respectively. 


\subsection{Performance of Fermentation using S.diastaticus}

\subsubsection{Fermentation at 24 hour}

Performance of $S$. diastaticus in fermenting acid hydrolysates was illustrated in Figure 4 (a), (b) and (c). Bioethanol yield was calculated based on the total sugar input from $30 \mathrm{~mL}$ of hydrolysates. Bioethanol concentration and bioethanol yield increased with increases of acid concentration, temperature and duration of pretreatment. High bioethanol content was produced at each upper limit of the investigated range with bioethanol concentration of $2.6 \mathrm{~g} / \mathrm{L}$ for treatment time of $45 \mathrm{~min}$ and $2.8 \mathrm{~g} / \mathrm{L}$ for acid concentration of $2.5 \% \mathrm{v} / \mathrm{v}$ and temperature of $125{ }^{\circ} \mathrm{C}$. Based on the HPLC analysis, most of the oligomerics found in the hydrolysates were consumed by $S$. diastaticus yeast after $24 \mathrm{hr}$ of fermentation time. Only cellobiose is not consumed by the yeast and contributes significant peaks in HPLC result. Fermentation time of $24 \mathrm{hr}$ is sufficient for $S$. diastaticus to take up most of the sugars presence in hydrolysates.

By increasing the acid concentration, reaction temperature and pretreatment time, the amount of glucose and other monomeric sugars produced in the respective sample increases. Glucose is one of the preferred carbohydrates which are readily consumed by $S$. diastaticus to produce bioethanol. Thus, by increasing glucose content, the amount of bioethanol produced increased as well. In addition, the fermentation environment is favourable for yeast as no inhibitors are found in hydrolysates based on HPLC analysis due to mild acid conditions.

Unlike S. cerevisiae, S. diastaticus is a type of yeast that is capable of fermenting starch and various types of sugar [20]. Based on the bioethanol yield achieved and the reduction in the sugar content, this prove that $S$. diastaticus is capable of consuming various type of sugars resulted from microalgae biomass especially glucose, galactose, mannose and dextrin to produce bioethanol as well as sustain their metabolism for growth.

The highest bioethanol yield produced is at about $94 \%$ based on the sugar input of $265.5 \mathrm{mg}$ from $30 \mathrm{~mL}$ of hydrolysates. Therefore, $50 \mathrm{~mL}$ of hydrolysates could produce $0.214 \mathrm{~g}$ bioethanol $/ \mathrm{g}$ biomass. Thus, $S$. diastaticus has the potential to be used as ethanologen yeast for the production of bioethanol. Besides, another advantageous property of using phosphoric acid is that when it is neutralised with sodium hydroxide, it produced sodium phosphate which can serve as macronutrient for the yeast. In addition, the use of mild acid to pretreat microalgae is more environmental friendly as it produces less corrosive waste. Moreover, the life-span of the process equipment involved can be extended due to lower risk of corrosion.
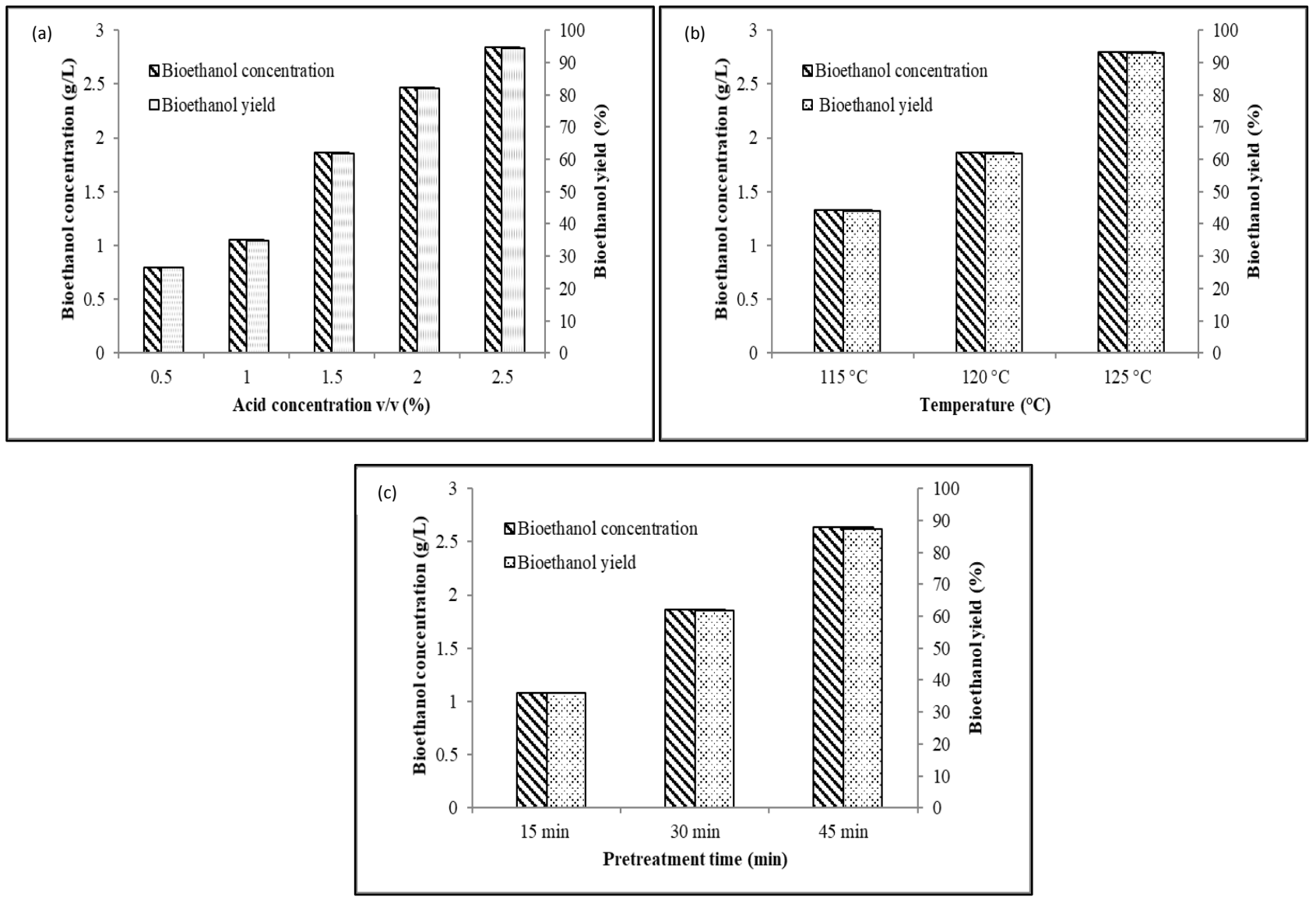

Figure 4. Performance of $S$. diastaticus in fermentation of acid hydroysates at various pretreatment condition. The hydrolysates were produced at: (a) various acid concentration. (b) pretreatment temperature (c) pretreatment duration. 


\subsubsection{Fermentation at 48 hour}

Based on Figure 5, the bioethanol content reduced significantly at $48 \mathrm{hr}$ of fermentation time. The main reason for the significant reduction in bioethanol content is that $S$. diastaticus started to utilise bioethanol as its carbon source for growth. The reduction in bioethanol suggested that the depletion of carbohydrate in the medium causes the starvation of the yeast which directs the yeast to consume bioethanol as its energy source in order to sustain its growth. This phenomenon was also observed in Harun and Danquah study [21], where the bioethanol content reduces after $30 \mathrm{hr}$ of fermentation. It can be concluded that $S$. diastaticus is a type of yeast which can utilise bioethanol as carbon source. Thus, a suitable fermentation time has to be determined or fedbatch fermentation process has to be employed in order to maximize the bioethanol yield.

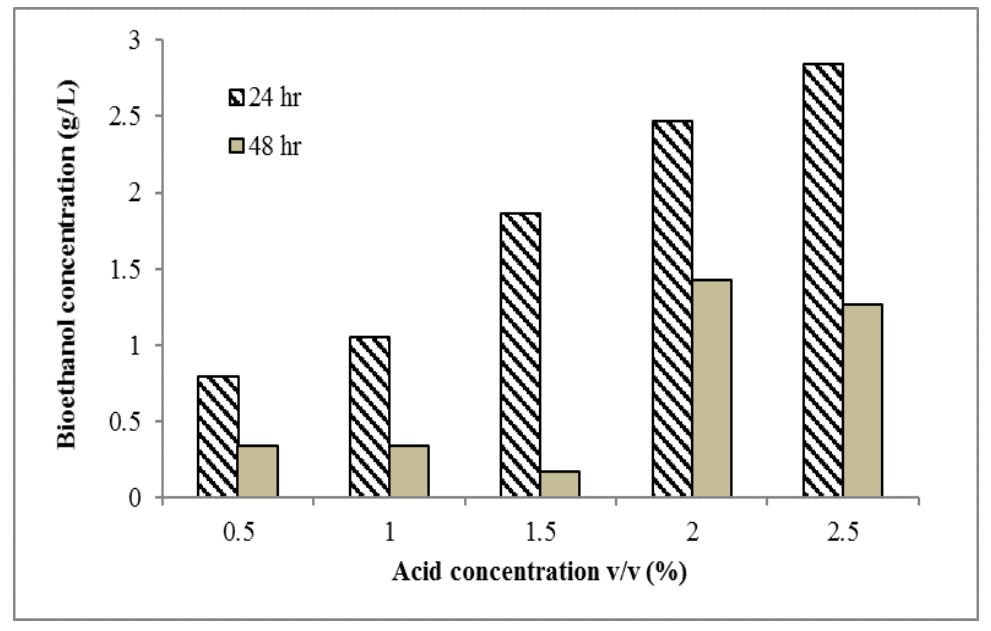

Figure 5. Bioethanol production of acid hydrolysates treated at various acid concentrations by using S. diastaticus for fermentation time at $24 \mathrm{hr}$ and $48 \mathrm{hr}$

\subsection{CONCLUSION}

Bioethanol was produced successfully from Scenedesmus dimorphus biomass after pretreated with phosphoric acid at mild condition. The fermentation process was carried out by $S$. diastaticus as the fermenting microbe. The highest bioethanol content achieved is $0.214 \mathrm{~g}$ bioethanol/ $\mathrm{g}$ biomass (94\%). Through this study, it is shown that the coordination between mild acid pretreatment with amylolytic yeast ( $S$. diastaticus) is capable in achieving high bioethanol yield. The maximum bioethanol yield was obtained at treatment condition of $2.5 \% \mathrm{v} / \mathrm{v}$ of phosphoric acid, at $120{ }^{\circ} \mathrm{C}$ for $30 \mathrm{~min}$.

\section{Acknowledgements}

The authors would like to acknowledge the funding given by the Universiti Tunku Abdul Rahman and Scenedesmus dimorphus biomass provided by Universiti Sains Malaysia for this project.

\section{References}

[1] Asada, C., Doi, K., Sasaki, C. \& Nakamura, Y. 2012. Efficient Extraction Of Starch From Microalgae Using Ultrasonic Homogenizer And Its Conversion Into Ethanol By Simultaneous Saccharification And Fermentation. Natural Resources. 3: 5.

[2] Ghasemi, Y., Rasoul-Amini, S., Naseri, A., Montazeri-Najafabady, N., Mobasher, M. \& Dabbagh, F. 2012. Microalgae Biofuel Potentials (Review). Applied Biochemistry and Microbiology. 48: 126-144.

[3] Millati, R. 2005. Ethanol production from lignocellulosic materials: Potential of continuous cultivation, immobilisation, and Zygomycetous fungi, Chalmers University of Technology.

[4] John, R. P., Anisha, G., Nampoothiri, K. M. \& Pandey, A. 2011. Micro And Macroalgal Biomass: A Renewable Source For Bioethanol. Bioresource Technology. 102: 186-193.

[5] Chng, L. M., Chan, D. J. \& Lee, K. T. 2016. Sustainable Production Of Bioethanol Using Lipid-Extracted Biomass From Scenedesmus Dimorphus. Journal of Cleaner Production.. 130: 68-73. 
[6] Biller, P. \& Ross, A. 2014. Pyrolysis GC-MS as a Novel Analysis Technique To Determine The Biochemical Composition Of Microalgae. Algal Research.. 6: 91-97.

[7] Andersen, R. A. 2005. 'Algal Culturing Techniques'. Academic Press.

[8] Castro, Y. A., Ellis, J. T., Miller, C. D. \& Sims, R. C. 2015. Optimization Of Wastewater Microalgae Saccharification Using Dilute Acid Hydrolysis For Acetone, Butanol, And Ethanol Fermentation. Applied Energy. 140: 14-19.

[9] Nguyen, M. T., Choi, S. P., Lee, J., Lee, J. H. \& Sim, S. J. 2009. Hydrothermal Acid Pretreatment of Chlamydomonas reinhardtii Biomass For Ethanol Production. Journal of Microbiology and Biotechnology. 19: 161-166.

[10] López-Linares, J., Cara, C., Moya, M., Ruiz, E., Castro, E. \& Romero, I. 2013. Fermentable Sugar Production From Rapeseed Straw By Dilute Phosphoric Acid Pretreatment. Industrial Crops and Products. 50: 525-531.

[11] Moxley, G. \& Zhang, Y.-H. P. 2007. More Accurate Determination Of Acid-Labile Carbohydrates In Lignocellulose By Modified Quantitative Saccharification. Energy \& Fuels. 21: 3684-3688.

[12] Silva, C., Ferreira, A., Dias, A. P. \& Costa, M. 2016. A Comparison Between Microalgae Virtual Biorefinery Arrangements For Bio-Oil Production Based On Lab-Scale Results. Journal of Cleaner Production. 130: 58-67.

[13] Simas-Rodrigues, C., Villela, H. D., Martins, A. P., Marques, L. G., Colepicolo, P. \& Tonon, A. P. 2015. Microalgae for economic applications: advantages and perspectives for bioethanol. Journal of Experimental Botany. 66: 4097-4108.

[14] Amutha, R. \& Gunasekaran, P. 2001. Production of Ethanol From Liquefied Cassava Starch Using Co-Immobilized Cells of Zymomonas mobilis and Saccharomyces diastaticus. Journal of Bioscience and Bioengineering. 92: 560-564.

[15] Pothiraj, C., Arun, A. \& Eyini, M. 2015. Simultaneous Saccharification And Fermentation Of Cassava Waste For Ethanol Production. Biofuel Research Journal. 2: 196-202.

[16] Ruiz, R. \& Date, T. E. 1996. Determination of Carbohydrates In Biomass By High Performance Liquid Chromatography. Laboratory Analytical Procedure No. 002, National Renewable Research Laboratory. Citeseer.

[17] Ehrman, T. 1996. Determination of Starch In Biomass Samples By Chemical Solubilization And Enzymatic Digestion. . Laboratory Analytical Procedure No. 016,. National Renewable Research Laboratory

[18] Stewart, G. G. \& Russell, I. 1987. Biochemistry and Genetics Of Carbohydrate Utilization By Industrial Yeast Strains. Pure and Applied Chemistry. 59: 1493-1500.

[19] Yazdani, P., Karimi, K. \& Taherzadeh, M. J. Improvement Of Enzymatic Hydrolysis Of A Marine Macro-Alga By Dilute Acid Hydrolysis Pretreatment. World Renewable Energy Congress-Sweden; 8-13 May; 2011; Linköping; Sweden, 2011. Linköping University Electronic Press, 186-191.

[20] Gilliland, R. 1966. Saccharomyces diastaticus - a Starch- Fermenting Yeast. Journal of the Institute of Brewing. 72: 271-275.

[21] Harun, R. \& Danquah, M. K. 2011. Influence of Acid Pre-Treatment On Microalgal Biomass For Bioethanol Production. Process Biochemistry. 46: 304309. 